\title{
The Prevalence, Predictors, and Consequences of Peripheral Sensory Neuropathy in Older Patients
}

\author{
James W. Mold, MD, MPH, Sara K. Vesely, PhD, Barbara A. Keyl, RN, \\ Joan B. Schenk, RN, and Michelle Roberts, $B A$
}

Background: The prevalence, predictors, and consequences of peripheral neuropathy in the elderly have not been well defined.

Metbods: Seven hundred ninety-five noninstitutionalized patients 65 years of age and older, recruited from the practices of family physicians, completed questionnaires and underwent peripheral neurologic examinations and tests of gait and balance. Variables included sociodemographic information, medical conditions, symptoms (numbness, pain, trouble with balance or walking, and restless legs), quality of life measures, ankle reflexes, position sense, vibratory sense, fine touch sensation, Tinnetti balance examination, and a 50-foot timed walk.

Results: The prevalence of at least one bilateral sensory deficit rose from $26 \%$ for 65 - to 74 -yearolds to $54 \%$ for those 85 and older. The most common deficit was loss of ankle reflex followed by loss of fine touch. Only $40 \%$ of those with bilateral deficits reported having a disease known to cause peripheral neuropathy. Predictors of bilateral deficits included increasing age, income less than $\$ \mathbf{1 5 , 0 0 0 , a}$ history of military service, increasing body mass index, self-reported history of diabetes mellitus, Vitamin $B_{12}$ deficiency or rheumatoid arthritis, and absence of a history of hypertension. Deficits were associated with numbness, pain, restless legs, trouble walking, trouble with balance, and reduced quality of life.

Conclusions: Peripheral sensory deficits are common in the elderly. In most cases, a medical cause is not obvious. Their consequences may not be as benign as often supposed. ( $\mathrm{J}$ Am Board Fam Pract 2004;17:309-18.)

Peripheral neurologic deficits are commonly found during physical examination of older patients. In fact, losses of vibratory sensation and ankle reflexes are so common that they are often listed in geriatric textbooks as normal physical findings in very old people. ${ }^{1,2}$ However, there is very little published information about their actual prevalence, patterns, and predictors.

Common causes of peripheral neuropathy include diabetes mellitus, alcoholism, and nutritional deficiencies (eg, thiamine, B12), infections (eg, HIV, Lyme disease), malignancies (eg, broncho-

Submitted, revised, 10 March 2004.

From the Departments of Family and Preventive Medicine (JWM, MR) and Biostatistics and Epidemiology (SKV), University of Oklahoma Health Sciences Center, Oklahoma City; Midwest City Regional Hospital Emergency Department, Midwest City, OK (BAK); and Wilmington, NC (JBS). Address correspondence to the James W. Mold, MD, MPH, Department of Family and Preventive Medicine, University of Oklahoma Health Sciences Center, $900 \mathrm{NE}$ $10^{\text {th }}$ Street, Oklahoma City, OK 73104 (e-mail: jamesmold@ouhsc.edu). genic carcinoma, renal cell carcinoma, lymphoma, multiple myeloma), and autoimmune diseases (eg, systemic lupus erythematosus, Sjogren syndrome, rheumatoid arthritis). A long list of environmental and pharmacological agents can also damage peripheral nerves. There are also many hereditary neuropathies (eg, hereditary sensory neuropathy types I, II, III, and IV, Krabbe disease, CharcotMarie-Tooth disease). Among adult patients referred for subspecialty evaluation, a specific cause can be identified in $72 \%$ of cases. ${ }^{3}$ However, referred patients are likely to have more severe or unusual symptoms and syndromes and therefore are probably not representative of the majority of patients seen by primary care physicians. The proportion of primary care patients with peripheral neuropathy for which a cause can be identified, other than age, is currently unknown.

There are changes in the structure and function of peripheral nerves that may be the result of the aging process itself. ${ }^{4-7}$ However, in the absence of 
disease, these changes are relatively minor and have, for the most part, not been associated with changes in clinical signs, symptoms, or the functional status. Just as Alzheimer disease, osteoarthritis, and presbycusis were once considered inevitable consequences of aging, "idiopathic" peripheral neuropathy has been neglected as a potentially preventable and/or treatable condition. Vrancken et $\mathrm{al}^{8}$ have demonstrated that age at onset of chronic idiopathic axonal polyneuropathy makes little difference in the neurological and electrophysiological findings, although patients with early onset and more rapid progression are more likely to become disabled, characteristics reminiscent of Alzheimer disease.

Idiopathic or age-related sensory neuropathy has received less attention than it deserves because it often seems to be asymptomatic. However, several researchers have identified a link between peripheral neuropathy and impaired balance and falls. ${ }^{9-14}$ Those prone to falls often limit their activities, leading to premature functional decline. It is also possible that a variety of lower extremity complaints such as leg cramps, restless legs syndrome, and nonspecific leg pains can result from neuropathy. ${ }^{15}$ An association between peripheral neuropathy and lower extremity ulcers, cellulitis, and amputations has not been excluded.

The purpose of the present study was to estimate the prevalence of peripheral neurological deficits in elderly primary care patients, to identify associated variables that might provide clues to the etiology of "idiopathic" peripheral neuropathy in this population, and to evaluate associations between neuropathy and adverse outcomes, including falls and health-related quality of life.

\section{Methods}

\section{Recruitment and Enrollment}

Between January 1, 1999, and December 31, 2000, patients $\geq 65$ years old were recruited from the practices of family physician members of the Oklahoma Physicians Resource/Research Network (OKPRN), a primary care practice-based research network in Oklahoma. Participating physicians generated lists of their patients $\geq 65$ years old who had been seen by them within the previous 18 months. From these lists, they deleted those who were no longer their patients, who were currently living in nursing homes, who were too confused to sign informed consent, or who had died. The practices sent a letter to the remaining patients on the lists explaining the study and inviting them to participate, followed in 2 weeks by a telephone call from the project coordinator.

Patients who agreed to participate were asked to complete a questionnaire sent to them 2 weeks before their enrollment visit. The questionnaire included demographic information (age, gender, ethnicity/race, education, income, history of military service), habits (use of alcohol and tobacco, dietary habits), medical conditions (diabetes mellitus, $\mathrm{B}_{12}$ deficiency, chronic hepatitis, renal failure, autoimmune diseases, peripheral neuropathy, etc), symptoms (numbness or weakness of extremities, trouble with balance, pain in extremities, restless legs, orthostatic lightheadedness, incontinence, etc), history of recent falls (within 3 months), functional status (activities of daily living, instrumental activities of daily living), and 3 measures of health related quality of life, the Quality of Well-Being Self-Administered Scale (QWB-SA), ${ }^{16}$ the Health Utilities Index (HUI-3), ${ }^{17}$ and the Medical Outcomes Study Short Form 36 (SF-36). ${ }^{18,19}$ Those who declined to participate were asked to provide information about why they were not interested, their current age and race, and their self-perceived state of health.

\section{Data Collection}

Patients were enrolled in their own family physicians' offices by one of 2 research nurses. At the enrollment visit, the nurses reviewed the study protocol and obtained informed consent. They reviewed the questionnaire for missing data and conducted a focused physical examination including weight, height, blood pressure and pulse in 3 positions, and examinations of fine touch in the feet, position of the great toe, vibration at the medial malleoli, and deep tendon reflexes at the ankles. Gait was assessed using a timed 50 -foot walk, ${ }^{20}$ and balance was scored using the Tinetti Balance Scale. $^{21}$

The 2 research nurses were trained by a neurologist to perform the peripheral neurological examination. The procedures used were as follows. Fine touch was measured using a 5.07 SemmesWeinstein monofilament. With eyes closed, the subject was asked to identify the number (1 or 2, called out by the examiner) coincident with the filament that touched the sole of the foot at each of 
8 different sites (1st, $3 \mathrm{rd}$, and 5 th toes and 1st, $3 \mathrm{rd}$, and 5 th metatarsals, and medial and lateral sole at the mid-foot). To be considered neurologically intact, the subject was required to be correct at 6 or more of the sites.

Position sensation was tested by asking the subject to indicate the direction (up or down) that the examiner manually moved their great toe while holding it lateromedially between thumb and first finger. To be considered intact, the subject had to be correct on 4 of 5 movements. Vibratory sense was tested using a C 128 tuning fork, struck with moderate force against the examiner's thenar eminence to produce vibration and applied to the subject's medial malleoli. Intact vibratory sensation was defined as a perception of vibration, buzzing, or tingling.

Ankle reflexes were tested using a standard triangular rubber-headed reflex hammer. Subject were seated with knees bent at $90^{\circ}$. With the ankle also at $90^{\circ}$, they were asked to gently press the sole of the foot into the examiner's hand as the Achilles tendon was tapped with moderate force. Any reflexive response was considered intact. Once the research nurses were comfortable with these skills, they separately examined the same group of 25 patients, blinded to the other's conclusions. Their findings were identical for all neurological findings (Chronbach $\alpha=100 \%$ ) except ankle reflex (87\%).

The questionnaire data were collected on Teleforms $^{22}$ that were scanned directly into a Microsoft Access database by a research assistant and then manually checked for accuracy. The physical examination data were collected on paper forms and entered manually into the same database.

\section{Statistical Analyses}

The dichotomized variables considered in these analyses included presence or absence of deep tendon reflexes at the ankles, position sense at the great toes, vibratory sense at the medial malleoli, and fine touch sensation in the soles of the feet. The prevalence of individual and combinations of peripheral sensory abnormalities were tabulated by age group ( 65 to 74,75 to 84 , and 85 and older) and for participants with and without a disease known to cause peripheral neuropathy (diabetes, vitamin $\mathrm{B}_{12}$ deficiency, chronic hepatitis $\mathrm{B}$ or $\mathrm{C}$, Crohn disease, lupus, scleroderma, rheumatoid arthritis, hereditary neuropathy, neurofibromatosis, or sarcoidosis).
Peripheral neuropathy was arbitrarily defined as the presence of one or more complete bilateral peripheral neurologic deficits. The decision to consider only bilateral deficits was intended to exclude cases of mononeuritis, radiculopathy, injuries, and strokes and to improve inter-rater reliability.

Bivariate ( $\chi^{2}$ and independent $t$ tests) and multivariable logistic regression methods were used to identify significant associations between peripheral neuropathy and sociodemographic variables, known disease-related risk factors, and other common diseases. Variables, which in the bivariate analyses had $P$ values less than .2, were considered for inclusion in the models. They were then removed one at a time based on highest $P$ value. The final models included all variables with $P$ values less than .05 .

$\chi^{2}$, independent $t$ tests, and multiple logistic and linear regression methods were then used to examine the association between peripheral neuropathy and various outcomes, including symptoms, functional status, falls, and quality of life scores.

\section{Results \\ Population}

Twenty-three physicians from 9 different practices within a 75-mile radius of Oklahoma City participated in the study. The total number of patients included on the physicians' original lists, before applying exclusion criteria, was 4025. Three hundred twenty-six were known to have died, 209 were currently in nursing homes, 159 were believed to be too confused to sign consent, and 778 had switched physicians, leaving 2553 potentially eligible patients. Seven hundred seventeen of these were unreachable by telephone after 3 or more attempts. One thousand twenty-six declined to participate; 87 cited transportation problems, 21 outof-state travel plans, 245 personal illness or illness of spouse, 406 lack of interest, and 267 said that they were just too busy.

Of the 810 who agreed to participate, 11 were excluded by the project coordinator because they were unable to understand the telephone instructions. The remaining 799 were enrolled. Among those who were enrolled, 4 had incomplete data and were excluded from these analyses. Participants were more likely than nonparticipants to be male (43\% vs. 37\%; $P=.002)$, younger $(P<.0001)$, better educated $(P<.0001)$, and in better (self- 
rated) health $(P<.0001)$. African Americans tended to be less willing to participate $(P=.06)$.

Participants had a mean age of 73.4 years (5.9), with a range of 64 to 94 (one patient aged 64 was inadvertently included). Fifty-six percent were female, and $86 \%$ were white. The mean body mass index of participants was 28.6. Two hundred nineteen $(27.5 \%)$ gave a history of at least one disease known to cause peripheral neuropathy. Other characteristics of the study population are shown in Table 1. There were relatively few participants $\geq 85$ years old, and most participants were highfunctioning and in relatively good health.

\section{Prevalence of Peripheral Neuropathy}

The prevalence of peripheral neuropathy by age group and by presence or absence of diseases known to cause peripheral neuropathy (diabetes, autoimmune diseases, chronic hepatitis $\mathrm{B}$ or $\mathrm{C}$, sarcoidosis, Crohn disease, and hereditary peripheral neuropathies) are shown in Table 2. Prevalence rates increased with increasing age only for those without a predisposing disease. Overall, those with a predisposing disease were twice as likely to have peripheral neuropathy $(45 \%$ vs. $26 \% ; P<$ $.0001)$. Only 17 participants (2\%) gave a history of peripheral neuropathy. Of these, 6 had no detectable bilateral sensory deficits. Table 3 shows the distribution of specific bilateral deficits and deficit patterns.

\section{Factors Associated with Peripheral Neuropathy}

Seventy-one percent of those with bilateral deficits had only one deficit, $22 \%$ had 2, 7\% had 3, and $1 \%$ had all 4 deficits. The most common bilateral deficit was the absence of ankle reflexes $(83 \%$ of those with deficits) followed by insensitivity to touch ( $31 \%$ of those with deficits), insensitivity to vibration (15\%), and insensitivity to position (7\%).

Significant bivariate associations were found between peripheral neuropathy and lower income and with self-reported history of military service, diabetes, $\mathrm{B}_{12}$ deficiency, and autoimmune disease. Education was also associated with peripheral neuropathy; high school graduates without further education had somewhat higher rates of neuropathy than those with either less or more education.

After controlling for all other variables in a multivariate logistic model, factors associated with peripheral neuropathy included age, income less than $\$ 15,000$, a history of military service, body mass
Table 1. Characteristics of Participants with Peripheral Neuropathy (PN) $(\mathbf{N}=795)$

\begin{tabular}{|c|c|c|c|}
\hline Variables & $\mathrm{N}$ & $\mathrm{PN}$ & $P$ \\
\hline $\begin{array}{l}\text { Age } \\
\quad 65 \text { to } 74 \\
75 \text { to } 84 \\
\geq 85\end{array}$ & $\begin{array}{r}795 \\
494 \\
262 \\
39\end{array}$ & $\begin{array}{l}26 \% \\
36 \% \\
54 \%\end{array}$ & .0001 \\
\hline $\begin{array}{l}\text { Body Mass Index: } \\
\quad>30 \\
<30\end{array}$ & $\begin{array}{l}264 \\
531\end{array}$ & $\begin{array}{l}38 \% \\
27 \%\end{array}$ & .0017 \\
\hline $\begin{array}{l}\text { Gender } \\
\text { Female } \\
\text { Male }\end{array}$ & $\begin{array}{l}795 \\
453 \\
342\end{array}$ & $\begin{array}{l}29 \% \\
33 \%\end{array}$ & .2053 \\
\hline $\begin{array}{l}\text { Race/Ethnicity } \\
\text { White } \\
\text { African American } \\
\text { Native American } \\
\text { Hispanic } \\
\text { Asian/Pacific Islander }\end{array}$ & $\begin{array}{r}795 \\
683 \\
68 \\
32 \\
10 \\
2\end{array}$ & $\begin{array}{r}31 \% \\
28 \% \\
41 \% \\
30 \% \\
0 \%\end{array}$ & .6965 \\
\hline $\begin{array}{l}\text { Education } \\
<\text { High School } \\
\text { High School } \\
>\text { High School }\end{array}$ & $\begin{array}{l}793 \\
120 \\
450 \\
223\end{array}$ & $\begin{array}{l}37 \% \\
27 \% \\
35 \%\end{array}$ & .0387 \\
\hline $\begin{array}{l}\text { Income } \\
<\$ 15,000 \text { per year } \\
\$ 15,000 \text { to } \$ 35,000 \text { per year } \\
>\$ 35,000\end{array}$ & $\begin{array}{l}763 \\
138 \\
338 \\
287\end{array}$ & $\begin{array}{l}41 \% \\
32 \% \\
25 \%\end{array}$ & .0061 \\
\hline $\begin{array}{l}\text { History of Military Service } \\
\text { Yes } \\
\text { No }\end{array}$ & $\begin{array}{l}787 \\
263 \\
524\end{array}$ & $\begin{array}{l}36 \% \\
28 \%\end{array}$ & .0316 \\
\hline $\begin{array}{l}\text { Current use of alcohol } \\
\text { None } \\
1 \text { to } 5 \text { drinks per week } \\
6 \text { to } 10 \text { drinks per week } \\
\geq 11 \text { drinks per week }\end{array}$ & $\begin{array}{r}795 \\
595 \\
140 \\
34 \\
20\end{array}$ & $\begin{array}{l}32 \% \\
29 \% \\
29 \% \\
20 \%\end{array}$ & .6150 \\
\hline $\begin{array}{l}\text { Current use of tobacco } \\
\text { Yes } \\
\text { No }\end{array}$ & $\begin{array}{r}795 \\
80 \\
715\end{array}$ & $\begin{array}{l}35 \% \\
30 \%\end{array}$ & .4079 \\
\hline $\begin{array}{l}\text { PN Diseases } \\
\text { Diabetes } \\
\text { Yes } \\
\text { No }\end{array}$ & $\begin{array}{l}133 \\
662\end{array}$ & $\begin{array}{l}47 \% \\
28 \%\end{array}$ & $<.0001$ \\
\hline $\begin{array}{l}\mathrm{B}_{12} \text { deficiency } \\
\text { Yes } \\
\text { No }\end{array}$ & $\begin{array}{r}41 \\
754\end{array}$ & $\begin{array}{l}46 \% \\
30 \%\end{array}$ & .0285 \\
\hline $\begin{array}{l}\text { Autoimmune disease } \\
\text { Yes } \\
\text { No }\end{array}$ & $\begin{array}{r}50 \\
745\end{array}$ & $\begin{array}{l}50 \% \\
30 \%\end{array}$ & .0026 \\
\hline $\begin{array}{l}\text { Chronic Hepatitis B or C } \\
\text { Yes } \\
\text { No }\end{array}$ & $\begin{array}{r}11 \\
784\end{array}$ & $\begin{array}{l}36 \% \\
31 \%\end{array}$ & .7456 \\
\hline $\begin{array}{l}\text { Hereditary neuropathy } \\
\text { Yes } \\
\text { No }\end{array}$ & $\begin{array}{r}5 \\
790\end{array}$ & $\begin{array}{l}60 \% \\
31 \%\end{array}$ & .1751 \\
\hline $\begin{array}{l}\text { Crohn disease } \\
\text { Yes } \\
\text { No }\end{array}$ & $\begin{array}{r}7 \\
788\end{array}$ & $\begin{array}{l}29 \% \\
31 \%\end{array}$ & 1.00 \\
\hline $\begin{array}{l}\text { Other Medical Conditions } \\
\text { Osteoarthritis } \\
\text { Yes } \\
\text { No }\end{array}$ & $\begin{array}{l}158 \\
637\end{array}$ & $\begin{array}{l}32 \% \\
31 \%\end{array}$ & .8311 \\
\hline $\begin{array}{l}\text { Hypertension } \\
\text { Yes } \\
\text { No }\end{array}$ & 362 & $\begin{array}{l}28 \% \\
33 \%\end{array}$ & .1228 \\
\hline $\begin{array}{l}\text { Hypercholesterolemia } \\
\text { Yes } \\
\text { No }\end{array}$ & $\begin{array}{l}285 \\
510\end{array}$ & $\begin{array}{l}28 \% \\
22 \%\end{array}$ & .1902 \\
\hline $\begin{array}{l}\text { Thyroid Problem } \\
\text { Yes } \\
\text { No }\end{array}$ & $\begin{array}{l}122 \\
673\end{array}$ & $\begin{array}{l}28 \% \\
31 \%\end{array}$ & .4246 \\
\hline
\end{tabular}

index, diabetes mellitus, vitamin $\mathrm{B}_{12}$ deficiency, rheumatoid arthritis, and absence of hypertension. There was an interaction between income and di- 


\begin{tabular}{llll}
\hline \multirow{2}{*}{$\begin{array}{l}\text { Age } \\
\text { Group }\end{array}$} & \multicolumn{2}{c}{ Patients with PN (n=246) } & All \\
\cline { 2 - 3 } 65 to 74 & No PN Disease & PN Disease* & $26 \%(130 / 494)$ \\
75 to 84 & $19.3(69 / 357)$ & $43 \%(61 / 143)$ & $36 \%(95 / 262)$ \\
$\geq 85$ & $31 \%(61 / 194)$ & $50 \%(34 / 68)$ & $54 \%(21 / 39)$ \\
$\geq 65$ (All) & $58 \%(18 / 31)$ & $38 \%(3 / 8)$ & $31 \%(246 / 795)$ \\
\hline
\end{tabular}

PN disease, self-reported history of diabetes mellitus, vitamin $\mathrm{B}_{12}$ deficiency, chronic hepatitis, Crohn disease, systemic lupus, scleroderma, rheumatoid arthritis, hereditary neuropathy, neurofibromatosis, or sarcoidosis. Association $\left(\chi^{2}\right)$ between PN and PN disease $(P<.0001)$. Association (Fisher's exact test) between age group and PN; for those without PN disease, $P<.0001$; for those with $\mathrm{PN}$ disease, $P=.5918$.

abetes mellitus. For persons with an income of less than $\$ 15,000$ or greater than $\$ 35,000$, diabetes was associated with peripheral neuropathy, but for those with an income of $\$ 15,000$ to $\$ 35,000$, no association could be demonstrated. The model is shown in Table 4.

\section{Possible Consequences of Peripheral Neuropathy}

The proportions of patients with one or more deficits who reported symptoms were as follows: numbness of extremities, $28 \%$; pain or discomfort, $48 \%$; restless legs, $31 \%$; trouble walking, $44 \%$; and trouble with balance, $35 \%$. Twenty-nine percent (72 of 246) reported none of these symptoms. Back and neck pain were not associated with neurologic deficits.

Table 3. Distribution of Neurologic Deficits in Participants with Peripheral Neuropathy $(\mathrm{N}=246)$

\begin{tabular}{lc}
\hline Deficit(s) & \% (Number with Deficits) \\
\hline deficit & $71(175)$ \\
Ankle reflex only & $59(145)$ \\
Position only & $1(3)$ \\
Touch only & $9(22)$ \\
Vibration only & $2(5)$ \\
2 deficits & $22(53)$ \\
Ankle and position & $1(3)$ \\
Ankle and touch & $11(28)$ \\
Ankle and vibration & $4(10)$ \\
Position and touch & $2(6)$ \\
Touch and vibration & $2(6)$ \\
3 deficits & $7(16)$ \\
Ankle, position, \& touch & $0.4(1)$ \\
Ankle, position, \& vibration & $1(2)$ \\
Ankle, touch, \& vibration & $5(12)$ \\
Position, touch, and vibration & $0.4(1)$ \\
4 deficits & $1(2)$ \\
Touch (small fibers) involved & $32(78)$ \\
Position involved & $7(18)$ \\
Vibration involved & $15(38)$ \\
Ankle reflex involved & $78(191)$ \\
\hline
\end{tabular}

Table 5 shows associations between neurologic deficits and selected symptoms, functional status indicators, and health-related quality of life scores after controlling for other variables. Peripheral neurologic deficits were associated with numbness in the extremities, restless legs, subjective trouble with gait and balance, objective trouble with balance, and reduced quality of life. There was no association, however, with number of reported falls or with more than one fall during the previous 3 months.

\section{Discussion}

\section{Literature Review}

A major obstacle to epidemiologic studies of symmetric peripheral sensory neuropathy has been the lack of agreement on a suitable operational definition. Definitions that require electrophysiologic studies (eg, nerve conduction studies), ${ }^{23}$ expensive equipment (eg, computer-assisted sensory examination), ${ }^{24}$ or invasive testing (eg, skin or nerve biopsy) ${ }^{15}$ make large studies impractical. Definitions that require symptoms (eg, the Michigan Diabetes Neuropathy Score $)^{25,26}$ exclude large numbers of people with asymptomatic disease. Many of the case definitions have been developed for people with specific diseases, most often diabetes mellitus. The choice of definition and study population for epidemiologic investigations should be based on the purpose of the investigation. We chose to focus on the objective signs available to primary care clinicians and on the population of older people who see them as patients, because we were primarily interested in gathering information that could inform clinical decision-making in this setting.

In a recent review of what is known about the prevalence of peripheral neuropathy in adults, 
Table 4. Factors Associated with Peripheral Neuropathy after Controlling for All Other Variables in a Logistic Regression Model

\begin{tabular}{llcl}
\hline Variables & Odds Ratio & $95 \%$ Confidence Interval \\
\hline Age & $1.08 /$ year & 1.05 to 1.11 \\
Body mass index & $1.06 /$ unit & 1.03 to 1.10 \\
Military service & 1.80 & 1.24 to 2.62 & \\
Rheumatoid arthritis & 2.92 & 1.49 to 5.73 & \\
Vitamin $B_{12}$ deficiency & 2.37 & 1.16 to 4.84 & If income $<\$ 15,000 / \mathrm{yr}$ \\
Hypertension & 0.63 & 0.44 to 0.89 & If income $\$ 15,000-\$ 35,000 / \mathrm{yr}$ \\
Diabetes mellitus & 2.71 & 1.67 to 4.39 & If income $>\$ 35,000 / \mathrm{yr}$ \\
\hline
\end{tabular}

Note: Hosmer-Lemeshow Goodness of Fit test had $\chi^{2}$ of 5.5152, $P=.7014(8 d f)$.

Martyn and Hughes ${ }^{27}$ could find only 3 population-based studies, none of which was conducted in the United States. Each of these studies looked only at people who were symptomatic and included both symmetric and asymmetric poly- and mononeuropathies. The prevalences reported were $8 \%$ in people over 55 years old in Italy, ${ }^{28} 2.4 \%$ in adults of all ages in Bombay, ${ }^{29}$ and $7 \%$ of all adults in Sicily based on symptoms alone. ${ }^{30}$

Odenheimer et $\mathrm{al}^{31}$ tabulated the neurological examination findings of a random sample of older people from East Boston who participated in the Established Populations for Epidemiologic Study of the Elderly (EPESE) project. The prevalence of decreased position sense at the great toe was $6 \%$ for 65 - to 74 -year-olds, $9 \%$ for 75 - to 84 -year-olds, and $13 \%$ for those $\geq 85$ years old. This is somewhat higher than the $2 \%, 2 \%$, and $8 \%$ rates that we found. Decreased vibratory sense at the great toe was documented in EPESE participants in 23\%, $35 \%$, and $47 \%$ respectively. Again, this is higher than our rates of $6 \%, 13 \%$, and $18 \%$. The differ-

Table 5. Associations between 1 or More and 2 or More Bilateral Peripheral Neurologic Deficits and Various Outcomes after Adjusting for Age, Gender, Race, Education, Income, Body Mass Index, and Presence of Disease Known to Cause Peripheral Neuropathy

\begin{tabular}{|c|c|c|}
\hline Outcome Variables & $1+$ Deficit & $2+$ Deficits \\
\hline \multicolumn{3}{|l|}{ Symptoms } \\
\hline Numbness arms/legs & $1.44(0.97,2.14)$ & $2.74(1.56,4.79)^{*}$ \\
\hline Pain or discomfort & $1.68(1.19,2.37)^{*}$ & $1.80(1.03,3.16)^{*}$ \\
\hline Restless legs & $1.40(0.96,2.04)$ & $2.15(1.23,3.74)^{*}$ \\
\hline Trouble walking & $1.50(1.04,2.17)^{*}$ & $2.62(1.47,4.67)^{*}$ \\
\hline Trouble with balance & $1.64(1.11,2.43)^{*}$ & $2.65(1.50,4.70)^{*}$ \\
\hline \multicolumn{3}{|l|}{ Falls in last 3 months } \\
\hline One fall & $1.22(0.80,1.84)$ & $1.07(0.56,2.03)$ \\
\hline$\geq 2$ falls & $1.53(0.83,2.81)$ & $1.17(0.46,2.97)$ \\
\hline \multicolumn{3}{|l|}{ Objective Findings } \\
\hline Tinetti Balance Score (0 to 16$)$ & $-1.12(-1.54,-0.70)^{*}$ & $-1.58(-2.26,-0.91)^{*}$ \\
\hline Timed $50-\mathrm{ft}$ walk (seconds) & $-0.12(-1.15,0.91)$ & $-0.08(-1.73,1.56)$ \\
\hline \multicolumn{3}{|l|}{ QOL/Functional Status } \\
\hline Self rated health (0 to 100$)$ & $-0.82(-3.53,1.89)$ & $-2.55(-6.87,1.77)$ \\
\hline SF-36 General Health (0 to 100$)$ & $-2.42(-5.47,2.63)$ & $-6.65(-11.48,-1.83)^{*}$ \\
\hline SF-36 Physical Functioning(0 to 100$)$ & $-7.06(-11.01,-3.10)^{*}$ & $-10.54(-16.89,-4.18)^{*}$ \\
\hline SF-36 Role Physical (0 to 100$)$ & $-5.09(-11.73,1.55)$ & $-8.16(-18.76,2.44)$ \\
\hline SF-36 Bodily Pain (0 to 100$)$ & $-3.36(-7.22,0.49)$ & $-5.96(-12.09,0.17)$ \\
\hline QWB-SA (0 to 1$)$ & $-0.027(-0.047,-0.006)^{*}$ & $-0.028(-0.61,0.004)$ \\
\hline HUI-3 (0 to 1$)$ & $-0.039(-0.074,-0.004)^{*}$ & $-0.046(-0.102,0.010)$ \\
\hline
\end{tabular}

Odds ratios and $95 \%$ confidence intervals derived from logistic regression models are given for symptoms $\beta$ coefficients and $95 \%$ confidence intervals derived from linear regression models are given for objective findings and QOL/functional status. Numbers are odds ratios (95\% confidence intervals) for symptom variables and $\beta$ coefficients ( $95 \%$ confidence intervals) for all other variables. ${ }^{*} P<.05$

QWB-SA, Quality of Well Being-Self-Administered Scale; HUI-3, Healthy Utility Index 3 Scale. 
ence may be attributed to the fact that the EPESE group rates represented both unilateral and bilateral decreased responses, whereas ours represent bilateral absent responses.

Impallomeni et $\mathrm{al}^{32}$ carefully assessed the ankle reflexes of 200 consecutive older patients admitted to the geriatric inpatient service of a hospital in England (mean age, 80; range, 65 to 99). They reported that only 9 patients $(4.5 \%)$ had bilaterally absent reflexes. Other researchers have found much higher percentages of older people to have this abnormality. For example, Howell ${ }^{33}$ reported that more than $50 \%$ of a group of community dwelling elders in England had no ankle reflexes, and Prakash and Stein ${ }^{34}$ found the rate of areflexia to be $38 \%$ among geriatric inpatients. However, these studies were published 54 and 30 years ago, respectively.

\section{Accuracy of Physical Examinations}

Questions can certainly be raised about the accuracy of the physical examination data. Under ideal circumstances, physical findings correlate closely but not perfectly with electrophysiological testing. ${ }^{35}$ Physical findings are obviously somewhat less sensitive than more sophisticated tests. ${ }^{36}$ Technique is important. For example, O'Keefe et $\mathrm{al}^{37}$ found that the plantar strike technique was more reliable than the traditional Achilles tendon strike method.

To minimize examination errors, we took several steps. The 2 examiners were trained by a neurologist, practicing on elderly volunteers with and without deficits. They then blindly examined the same set of 25 patients, with almost perfect agreement. For a finding to be considered absent, there had to be essentially no response.

\section{Prevalence and Significance}

It is easy to dismiss common impairments in older patients, assuming them to be the result of aging and/or wear and tear. However, when we do this, we miss opportunities for the development of specific preventive and therapeutic interventions. Alzheimer disease, osteoarthritis, and presbycusis are good examples of conditions once thought to be the inevitable consequence of aging. Peripheral sensory neuropathy could be the result of an unidentified set of diseases or exposures that could be prevented and/or treated. Although aging itself may be a contributor, it is not an invariable and sufficient cause, because $46 \%$ of patients $\geq 85$ years old in our study had no deficits.

There was no apparent increase in prevalence with age for patients with a disease known to cause peripheral neuropathy, which supports the notion that "idiopathic" (also called "cryptogenic") peripheral neuropathy may have a different set of causes. In referred populations, the percentage of peripheral neuropathy patients with no identifiable cause ranges from $10 \%$ to $23 \% .{ }^{38}$ However, these estimates are likely to be skewed by referral bias, because older patients with fewer symptoms are less likely to be referred. In referred populations, however, idiopathic peripheral neuropathy is more common with increasing age. For example, Verghese et $\mathrm{al}^{39}$ found that $39 \%$ of those aged $\geq 80$ but only $9 \%$ of those aged 65 to 79 were classified as idiopathic.

\section{Clues to Etiologies}

After controlling for age and diseases known to cause peripheral neuropathy, there was an association of neuropathy with lower income. This is in contrast to the findings of Alvarez and Idiaquez, ${ }^{40}$ who compared the rates of ankle areflexia between older persons from groups of higher and lower socioeconomic status and found an overall rate of $6 \%$ with no significant difference between groups. Participants with neurologic diseases and medications known to cause neuropathy and orthostatic hypotension were excluded from their study. We found no relationships between peripheral neuropathy and gender, race, education, or occupation after controlling for income, and we could find no studies in the literature that investigated these variables.

The association between neuropathy and past military service is intriguing. We did not collect information about past use of alcohol (only current use), so we cannot rule out alcohol as a confounder. On the other hand, service in the military may have been associated with exposure to other neuropathic agents.

Patients with higher body mass index were more likely to have neuropathy, even after controlling for diabetes, which suggests several possibilities. It is likely that some of these patients had undiagnosed diabetes, because people who are overweight are more likely to have diabetes, and there is some evidence that undetected diabetes is associated with at least some cases of neuropathy. ${ }^{41}$ Another pos- 
sibility is that neuropathy is caused in part by nerve compression or by trauma associated with weightbearing. On the other hand, neuropathy may lead to inactivity with resultant weight gain. Finally, examination may be less accurate in obese patients.

The relationship between peripheral neuropathy and hypertension is particularly interesting. If our findings are correct, hypertension and/or its treatment may actually be protective. This is in sharp contrast to the findings of Zarelli et al, ${ }^{42}$ who found that Italian primary care patients with hypertension were 4.5 times more likely to have chronic symmetrical neuropathy after controlling for diabetes and other relevant factors. Aside from the difference in demographics, their study included only those with symptoms related to their neuropathy, and they included patients $\geq 55$ years old. This is an important issue for further investigation, because hypertension is a risk factor for vascular disease, which could be a cause of "idiopathic" neuropathy, a possibility supported by a case-control study conducted in the Netherlands. ${ }^{43}$

It is worth mentioning that $\mathrm{B}^{12}$ deficiency (selfreported and presumably treated) was associated with peripheral neurologic deficits. It has been shown in a number of studies done in a variety of populations that $B_{12}$ deficiency is extremely common in the elderly (prevalence $10 \%$ to $20 \%$ in unscreened patients) and grossly underdiagnosed. ${ }^{44}$

\section{Possible Consequences}

Peripheral neuropathy was associated with symptoms and with lower health-related quality of life. This has been documented by others, ${ }^{45-47}$ although we were unable to confirm the association with falls that others have observed..$^{10-14,32,48}$ This supports our contention that peripheral neuropathy in the elderly is not trivial. However, it certainly seems to be underdiagnosed. Only 11 of the 175 patients that we identified reported a history of peripheral neuropathy. Six more gave a history of neuropathy but did not have bilateral sensory deficits. In these cases, the diagnosis may have been based on symptoms or more sensitive tests.

\section{Limits of Generalizability}

Our study population was drawn from the practices of the physician members of a practice-based research network in Oklahoma, OKPRN. Members of practice-based research networks have been shown to be very similar to other primary care physicians, ${ }^{49}$ and it is therefore reasonable to assume that the sampling frame chosen was representative of the patients of family physicians at least, if not all primary care physicians. However, enrolled patients were clearly younger and healthier than those who declined to participate. This may have resulted in an underestimation of the true prevalence of peripheral neuropathy in this population. Because gender and race were unrelated to prevalence of neurologic deficits, differences between participants and nonparticipants with respect to these characteristics should have had minimal impact on our findings. Our findings cannot be generalized to people living in nursing homes or to those with significant cognitive impairments. All medical history was by self-report and was unconfirmed.

Even with these limitations, our prevalence estimates and the frequencies of deficit patterns should be of help to clinicians and researchers, given the paucity of such data in the prior literature. Because this study was part of a longitudinal cohort study, we should have the opportunity to evaluate the incidence and progression of peripheral neuropathy over time and include other outcome measures, such as hospitalization and death.

\section{References}

1. Shaumberg HH, Spencer PS, Ochoa J. The aging human peripheral nervous system. In: Katzman R, Terry RD, editors. The neurology of aging. Philadelphia: Davis; 1983.

2. Jordan B, Cummings JL. Mental status and neurologic examination in the elderly. In: Hazzard WR, Blass JP, Ettinger WH, Jr., et al, editors. Principles of geriatric medicine and gerontology. New York: McGraw-Hill; 1999.

3. George J, Twomey JA. Causes of polyneuropathy in the elderly. Age Ageing 1986;15:247-9.

4. Dorfman LJ, Bosley TM. Age-related changes in peripheral and central nerve conduction in man. Neurology 1979;29:38-44.

5. Bouche P, Cattelin F, Saint-Jean O, et al. Clinical and electrophysiological study of the peripheral nervous system in the elderly. J Neurol 1993;240:263-8.

6. Taylor PK. Non-linear effects of age on nerve conduction in adults. J Neurol Sci 1984;66:223-34.

7. Jacobs JM, Love S. Qualitative and quantitative morphology of human sural nerve at different ages. Brain 1985;108:897-924.

8. Vrancken AF, Franssen H, Wokke JH, Teunissen LL, Notermans NC. Chronic idiopathic axonal polyneuropathy and successful aging of the periph- 
eral nervous system in elderly people. Arch Neurol 2002;59:533-40.

9. Richardson JK. The clinical identification of peripheral neuropathy among older persons. Arch Phys Med Rehabil 2002;83:1553-8.

10. Koski K, Luukinen H, Laippala P, Kivela SL. Risk factors for major injurious falls among the homedwelling elderly by functional abilities. A prospective population-based study. Gerontol 1998;44:232-8.

11. Luukinen H, Koski K, Laippala P, Kivela SL. Predictors for recurrent falls among the home-dwelling elderly. Scand J Prim Health Care 1995;13:294-9.

12. Sorock GS, Labiner DM. Peripheral neuromuscular dysfunction and falls in a elderly cohort. Am J Epidemiol 1992;136:584-91.

13. Richardson JK, Hurvitz EA. Peripheral neuropathy: a true risk factor for falls. J Gerontol Med Sci 1995; 50A:M211-5.

14. Richardson JK, Ching C, Hurvitz EA. The relationship between electromyographically documented peripheral neuropathy and falls. J Am Geriat Soc 1992; 40:1008-12.

15. Holland NR, Crawford TO, Hauer P, et al. Smallfiber sensory neuropathies: clinical course and neuropathology of idiopathic cases. Ann Neurol 1998; 44:47-59.

16. Andresen EM, Rothenberg BM, Kaplan RM. Performance of self-administered mailed version of the quality of well-being (QWB-SA) questionnaire among older adults. Med Care 1998;36:1349-60.

17. Torrance GW. Measurement of health state utilities for economic appraisal. J Health Econ 1986;5:1-30.

18. Ware JE, Snow KK, Kosinski M, Gandek B. SF-36 health survey manual and interpretation guide. Boston: New England Medical Center, The Health Institute; 1993.

19. Lyons RA, Perry HM, Littlepage BN. Evidence for the validity of the short-form 36 questionnaire (SF36) in an elderly population. Age Ageing 1994;23: 182-4.

20. Cooperating Clinics Committee of the American Rheumatism Association. A seven day variability study of 499 patients with peripheral rheumatoid arthritis. Arthritis Rheum 1965;8:302-34.

21. Raiche M, Hebert R, Prince F, Corriveau H. Screening older adults at risk of falling with the Tinetti balance scale. Lancet 2000;356:1001-2.

22. Teleform Standard (version 6). San Marcus (CA): Cardiff Software, Inc.; 1998.

23. Gerr F, Letz R. Epidemiological case definitions of peripheral neuropathy: experience from two neurotoxicity studies. Neurotoxicol 2000;21:761-8.

24. Dyck PJ, O'Brien PC, Kosanke JL, Gillen DA, Karnes JL. A 4, 2, and 1 stepping algorithm for quick and accurate estimation of cutaneous sensation threshold. Neurology 1993;43:1508-12.

25. Feldman EL, Stevens MJ, Thomas PK, Brown MB,
Canal N, Greene DA. A practical two-step quantitative clinical and electrophysiological assessment for the diagnosis and staging of diabetic neuropathy. Diabetes Care 1994;17:1281-9.

26. Lunetta M, Le Moli R, Grasso G, Sangiorgio L. A simplified diagnostic test for ambulatory screening of peripheral diabetic neuropathy. Diabetes Res Clin Pract 1998;39:165-72.

27. Martyn CN, Hughes RA. Epidemiology of peripheral neuropathy. J Neurol Neurosurg Psychiatry 1997;62:310-8.

28. Beghi E, Monticelli ML. Chronic symmetric symptomatic polyneuropathy in the elderly: a field screening investigation of risk factors for polyneuropathy in two Italian communities. Italian General Practitioner Study Group (IGPST). J Clin Epidemiol 1998;51:697-702.

29. Bharucha NE, Bharucha AE, Bharucha EP. Prevalence of peripheral neuropathy in the Parsi community of Bombay. Neurology 1991;41:1315-7.

30. Savettieri G, Rocca WA, Salemi G, et al. Prevalence of diabetic neuropathy with somatic symptoms: a door-to-door survey in two Sicilian municipalities. Sicilian Neuro-Epidemiologic Study (SNES) Group. Neurology 1993;43:1115-20.

31. Odenheimer G, Funkenstein HH, Beckett L, et al. Comparison of neurologic changes in 'successfully aging' persons vs the total aging population. Arch Neurol 1994;51:573-80.

32. Impallomeni M, Kenny RA, Flynn MD, Kraenzlin M, Pallis CA. The elderly and their ankle jerks. The Lancet 1984;325:670-2.

33. Howell TH. Senile deterioration of the central nervous system. A clinical study. Br Med 1949;56-8.

34. Prakash C, Stein G. Neurological signs in the elderly. Age Ageing 1973;2:24-7.

35. Richardson JK. Factors associated with falls in older patients with diffuse polyneuropathy. J Am Geriat Soc 2002;50:1767-73.

36. Gin H, Rigalleau V, Baillet L, Rabemanantsoa C. Comparison between monofilament, tuning fork and vibration perception tests for screening patients at risk of foot complication. Diabetes Metab 2002;28: 457-61.

37. O'Keeffe ST, Smith T, Valacio R, Jack CI, Playfer JR, Lye M. A comparison of two techniques for ankle jerk assessment in elderly subjects. Lancet 1994;344: 1619-20.

38. Wolfe GI, Barokn RJ. Cryptogenic sensory and sensorimotor polyneuropathies. Semin Neurol 1998; 118:105-11.

39. Verghese J, Bieri PL, Gellido C, Schaumburg HH, Herskovitz S. Peripheral neuropathy in youngold and old-old patients. Muscle Nerve 2001;24: $1476-81$.

40. Alvarez G, Idiaquez J. Differences in postural hypotension and ankle jerks in the elderly from two con- 
trasting socio-economic levels. Clin Auton Res 1991; $1: 234-4$.

41. Novella SP, Inzucchi SE, Goldstein JM. The frequency of undiagnosed diabetes and impaired glucose tolerance in patients with idiopathic sensory neuropathy. Muscle Nerve 2001;24:1229-31.

42. Zarrelli MM, Amoruso L, Beghi E, et al. Arterial hypertension as a risk factor for chronic symmetric polyneuropathy. J Epidemiol Biostat 2001;6:409-13.

43. Teunissen LL, Franssen H, Wokke JH, et al. Is cardiovascular disease a risk factor in the development of axonal polyneuropathy. J Neurol Neurosurg Psychiatry 2002;72:590-5.

44. Stabler SP, Lindenbaum J, Allen RH. Vitamin B-12 deficiency in the elderly: current dilemmas. Am J Clin Nutr 1997;66:741-9.

45. Teunissen LL, Eurelings M, Notermans NC, Hop
JW, van Gijn J. Quality of life in patients with axonal polyneuropathy. J Neurol 2000;247:195-9.

46. Meyer-Rosberg K, Kvarnstrom A, Kinnman E, Gordh T, Nordfors LO, Kristofferson A. Peripheral neuropathic pain - a multidimensional burden for patients. Eur J Pain 2001;5:379-89.

47. Meyer-Rosberg K, Burckhardt CS, Huizar K, Kvarnstrom A, Nordfors LO, Kristofferson A. A comparison of SF-36 and Nottingham Health Profile in patients with chronic neuropathic pain. Eur J Pain 2001;5:391-403.

48. Schwartz AV, Hillier TA, Sellmeyer DE, et al. Older women with diabetes have a higher risk of falls: a prospective study. Diabetes Care 2002;25:1749-54.

49. Nutting PA, Baier M, Werner JJ, Cutter G, Reed FM, Orzano AJ. Practice patterns of family physicians in practice-based research networks: a report from ASPN. Ambulatory Sentinel Practice Network. J Am Board Fam Pract 1999;12:278-84. 